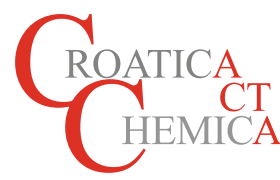

\title{
Silicon Nanowires Substrates Fabrication for Ultra-Sensitive Surface Enhanced Raman Spectroscopy Sensors
}

Hrvoje Gebavi, ${ }^{1,2}$ Lara Mikac, ${ }^{1,2}$ Marijan Marciuš, ${ }^{3}$ Mile Šikic, ${ }^{4}$ Vlasta Mohaček-Grošev,,${ }^{1,2}$ Tibor Janči, ${ }^{5}$ Sanja Vidaćek, ${ }^{5}$ Emina Hasanspahić, ${ }^{6}$ Enisa Omanović Miklićanin, ${ }^{6}$ Mile Ivanda ${ }^{1,2, *}$

\footnotetext{
${ }_{1}$ Center of Excellence for Advanced Materials and Sensing Devices, Research Unit New Functional Materials, Bijenička cesta 54, HR-10000 Zagreb, Croatia

2 Ruđer Bošković Institute, Division of Materials Physics, Laboratory for Molecular Physics, Bijenička cesta 54, HR-10000 Zagreb, Croatia

3 Ruđer Bošković Institute, Division of Materials Chemistry, Laboratory for Synthesis of New Materials, Bijenička cesta 54, HR-10000 Zagreb, Croatia

4 Faculty of Electrical Engineering and Computing, Unska 3, HR-10000 Zagreb, Croatia

5 University of Zagreb, Faculty of Food Technology and Biotechnology, Department of Food Engineering, Laboratory for Meat and Fish Technology, Pierottijeva 6, HR-10000 Zagreb, Croatia

6 University of Sarajevo, Faculty of Agricultural and food science, Zmaja od Bosne 8, BA-71000 Sarajevo, Bosnia and Herzegovina

* Corresponding author's e-mail address: ivanda@irb.hr
}

RECEIVED: April 11, 2017 \REVISED: July 6, 2017 « ACCEPTED: July 7, 2017

THIS PAPER IS DEDICATED TO PROF. MIRJANA METIKOŠ-HUKOVIĆ ON THE OCCASION OF HER BIRTHDAY

Abstract: The silicon based substrates for surface enhanced Raman spectroscopy (SERS) have been synthesized and tested. The silver-assisted electroless wet chemical etching method has been utilized for silicon nanowires production which has been proved as the promising SERS substrate. The morphology of the silicon nanowires coated with silver nanoparticles has been examined by scanning electron microscopy. The SERS measurements tested on rhodamine $6 \mathrm{G}$ molecules indicated the optimal silicon nanowire substrate production obtained for 5 M hydrofluoric acid and $30 \mathrm{mM}$ silver nitrate etching solution. The results show SERS detection limit of $10^{-8} \mathrm{M}$ rhodamine in aqueous solution.

Keywords: electroless chemical etching, surface enhanced Raman spectroscopy, silicon nanowires, rhodamine.

\section{INTRODUCTION}

E XTENSIVE scientific efforts have been directed towards advanced and optimized substrates for surface enhanced Raman spectroscopy (SERS) applications. ${ }^{[1-6]}$ Thanks to its high trace level detection and chemical fingerprint identification, SERS became one of the well accepted scientific tools which still looks for its development, novel applications and market. ${ }^{[7,8]}$

SERS signal intensity depends on analyte - plasmons interaction i.e. electromagnetic energy localised between two adjacent metal nanoparticles (NPs) allows the enhancement of usually weak intensity analyte molecules vibrations. Therefore the choice of the appropriate substrate for a specific analyte and the analyte vicinity to metal NP is of the high importance. ${ }^{[9,10]}$ Among non-colloidal substrates, silicon nanostructures such as porous silicon ${ }^{[6]}$ and silicon nanowires ${ }^{[2-5,7]}$ (SiNWs) draw attention owing to their low-cost fabrication and high SERS measurement reproducibility. SiNWs can be produced by chemical vapour deposition, laser ablation, vapour transport and condensation, molecular beam epitaxy, annealing of catalytic nanoclusters on silicon, solution growth, and catalytic etching. ${ }^{[7]}$ Electroless wet chemical etching (EWCE) method ${ }^{[1]}$ is recognized as the simple and cost-effective process which allows the formation of uniform silicon nanowires distribution over a wide area preserving high reproducibility and homogeneity. ${ }^{[1]}$ The method is based on hydrofluoric acid (HF) and silver nitrate $\left(\mathrm{AgNO}_{3}\right)$ assisted etching of silicon wafer. SiNWs have been synthesized on ' $n$ ' and ' $p$ ' types of wafers with (100), (110), and (111) orientations for various temperatures and the etching solution concentrations. ${ }^{[1]}$ 
EWCE method gives vertically oriented SiNWs whose coating can be performed by sputtering, ${ }^{[11]}$ evaporation ${ }^{[12]}$ or dipping into Ag or Au solution. ${ }^{[1,13]}$ Recently, a very large signal enhancement and $10^{-15} \mathrm{M}$ rhodamine concentration detection were obtained by careful SiNWs plating utilizing $\mathrm{HF}$ and $\mathrm{AgNO}_{3}$ solution. Except SiNWs density and height, the critical factors were $\mathrm{HF}$ and $\mathrm{AgNO}_{3}$ concentration and SiNWs dipping time. ${ }^{[14]}$ SiNWs can be also tapered and their surface roughness increased which additionally contributes to SERS enhancement.[15]

The goal of this paper was to fabricate SiNWs and test their SERS features. The SiNW samples were synthetized by EWCE method and decorated with Ag nano-sphere particles. The influence of $\mathrm{AgNO}_{3}$ concentration and etching time were examined while the SERS features were tested on rhodamine 6G (R6G) molecules.

\section{MATERIALS AND METHODS}

Silicon wafers (100 orientation, single crystalline $p$-type with a resistivity of $0.5-1 \Omega \mathrm{cm}$ ) were cleaned with standard RCA (Radio Corporation of America) cleaning processes. ${ }^{[16]}$ The mixtures of hydrofluoric acid $(5 \mathrm{M})$ and various $\mathrm{AgNO}_{3}$ concentrations $(20,30,40 \mathrm{mM})$ in aqua were utilized for synthesizing silicon nanowires by electroless wet chemical etching. ${ }^{[1]} \mathrm{A}$ grey silver layer which covers a sample was removed with $\mathrm{NH}_{4} \mathrm{OH}: \mathrm{H}_{2} \mathrm{O}_{2}=3: 1(v / v)$ solution. Subsequently, the samples were rinsed with $\mathrm{mQ}$ $(18.2 \mathrm{M} \Omega \cdot \mathrm{cm})$ water and dried. All experiments were carried out at room temperature of $25{ }^{\circ} \mathrm{C}$. All chemicals were purchased from Alfa Aesar (99\%) except HF (48\%) purchased from Normapur.

After the first step, the second step decorates SiNWs with $\mathrm{Ag}$ nanoparticles (AgNPs). Again, as in the SiNWs formation step, the 20,30, $40 \mathrm{mM} \mathrm{AgNO}_{3}$ solutions were prepared and the samples were dipped into the solution during $3 \mathrm{~min}$ period.

The morphologies of the synthesized samples and their SiNWs and AgNPs dimensions were examined by Jeol
JSM 7000F scanning electron microscope. Samples were tilted for $45^{\circ}$ during each scan.

SERS measurements were performed on Jobin Yvon T64000 Raman spectrometer in micro Raman configuration with $514.5 \mathrm{~nm}$ argon laser excitation. The laser power on the sample was $\sim 2 \mathrm{~mW}$. Each spectrum was recorded 3 times for $30 \mathrm{~s}$. Prior to SERS monitoring, a drop of $10^{-6} \mathrm{M}$ and $10^{-8} \mathrm{M}$ rhodamine $6 \mathrm{G}$ aqueous solution (R6G) was dried on the prepared substrates for several minutes.

\section{RESULTS AND DISCUSSION}

Figure 1. shows SEM figures of silicon nanowires typical for EWCE obtained for different $\mathrm{AgNO}_{3}$ concentrations in etching solutions. The final step for SERS active surface synthesis was obtained by silver nanoparticles (AgNPs) coating. Figure 1.a shows SiNWs substrate obtained by $30 \mathrm{mM}$ $\mathrm{AgNO}_{3}$ concentration during 120 min etching process. Figures b) and c) are obtained present SiNWs after $60 \mathrm{~min}$ etching decorated with AgNPs obtained from 30 and $40 \mathrm{mM} \mathrm{AgNO}_{3}$ concentration, respectively.

Several SiNWs in the tree like morphology (Figure 1b) can also merge and create characteristic sheets (Figure 1c). AgNPs size ranged from 50 to $200 \mathrm{~nm}$ (Figure 1). The height of the SiNWs was from 5 to $10 \mu \mathrm{m}$ depending on etching time and monitored sample point. The single SiNW diameter was uniform over the whole length irrespective of etching time and $\mathrm{AgNO}_{3}$ concentration ranging from 50 $150 \mathrm{~nm}$. The AgNPs were placed mostly on the top of the SiNWs (Figure 1.a), but AgNPs close to the silicon wafer were also observed (Figure 1.c). SiNWs have intentions to create cone shaped bundles (Figure 1.c). As the consequence the AgNPs merge together or come to a vicinity of several nanometers, creating wider silver areas at the SiNWs top ensuring adequate SERS signal. It is also observed that samples have certain areas with different SiNW growth directions.

The obtained substrates (SiNWs covered with AgNPs) were tested as the SERS substrate for rhodamine 6G
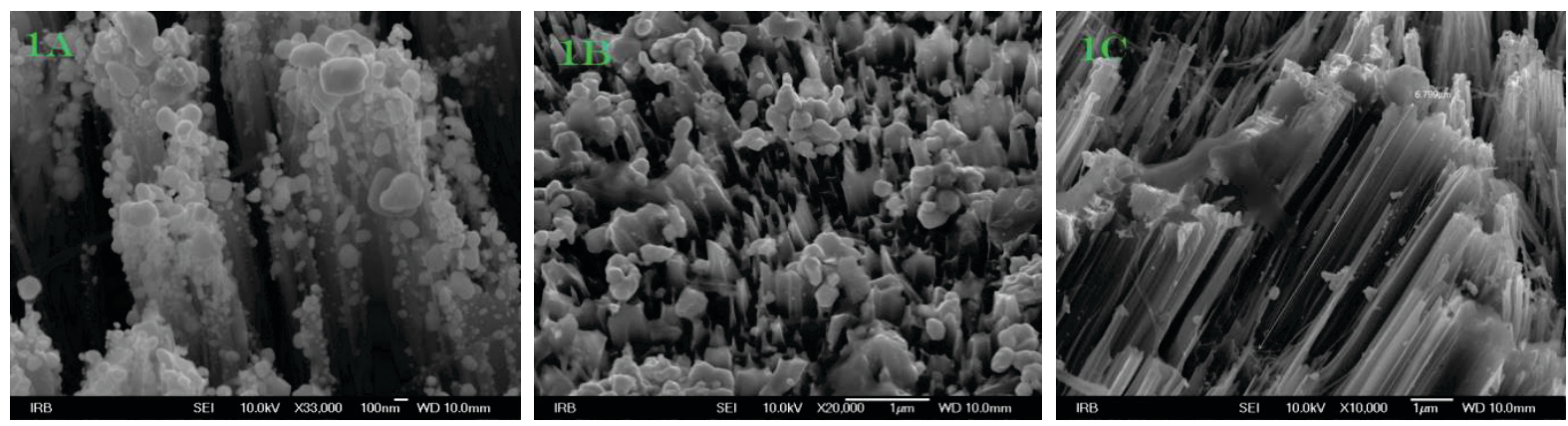

Figure 1. SiNW array decorated with AgNPs obtained with various etching time and $\mathrm{AgNO}_{3}$ concentrations: (A) 120 min etching, $30 \mathrm{mM} \mathrm{AgNO}_{3}$, (B) 60 min etching, $30 \mathrm{mM} \mathrm{AgNO}_{3}$, and (C) 60 min etching time, $40 \mathrm{mM} \mathrm{AgNO}_{3}$. 
molecule. The typical R6G bends at $612,774,1123,1185$, $1245,1315,1509,1612,1650 \mathrm{~cm}^{-1}$ (Ref. [17]) were monitored (Figure 2.) for two different R6G concentrations, 10-6 and $10^{-8} \mathrm{M}$.

Furthermore, the absolute value of $612 \mathrm{~cm}^{-1}$ band was monitored for all samples and various $\mathrm{AgNO}_{3}$ concentrations in the case of $10^{-6} \mathrm{M} \mathrm{R6G}$ solution (Figure 3.).

The SiNWs array formation mechanism is based on localized microscopic electrochemical cell model where the $\mathrm{Ag}^{+}$shows the features of a cathode while it's surrounding, the Si wafer has the function of an anode. ${ }^{[2-5,14]}$

The cone shaped bundles creation can be partially correlated with the SiNWs elasticity and surface tension during drying process. ${ }^{[1]}$ Furthermore, the van der Waals force influences the SiNWs tips ${ }^{[1]}$ and stick them more as the etching time increases. However, the various SiNWs growth orientations observed on different samples cannot be attributed to the surface tension, but rather to fluctuations during etching process. The bubbling during the silver layer removal step with $\mathrm{NH}_{4} \mathrm{OH}: \mathrm{H}_{2} \mathrm{O}_{2}=3: 1$ solution is quite intensive process which can influence the surface morphology by causing SiNWs breakage which is observed especially for higher $\mathrm{AgNO}_{3}$ concentrations and etching times.

In Ref. [1] is claimed a linear correlation between SiNWs length and etching time for the period shorter than $120 \mathrm{~min}$ as well as the growth rate of $0.25 \mu \mathrm{m} \mathrm{min}^{-1}$ at room temperature and $20 \mathrm{mM} \mathrm{AgNO}_{3}$ concentration. In our case, for the $40 \mathrm{mM} \mathrm{AgNO}_{3}$ concentration, the growth rate was somewhat smaller i.e., $\sim 0.13 \mu \mathrm{m} \mathrm{min}{ }^{-1}$. Furthermore, Figure 1 of Ref. [1] suggested a decrease of the SiNWs length from approx. 20 to $17 \mu \mathrm{m}$ as the concentration decreases from 40 to $30 \mathrm{mM} \mathrm{AgNO}_{3}$, respectively. Considering this slight change of the SiNWs length with $\mathrm{AgNO}_{3}$ concentration we do not expect drastic SiNWs length change

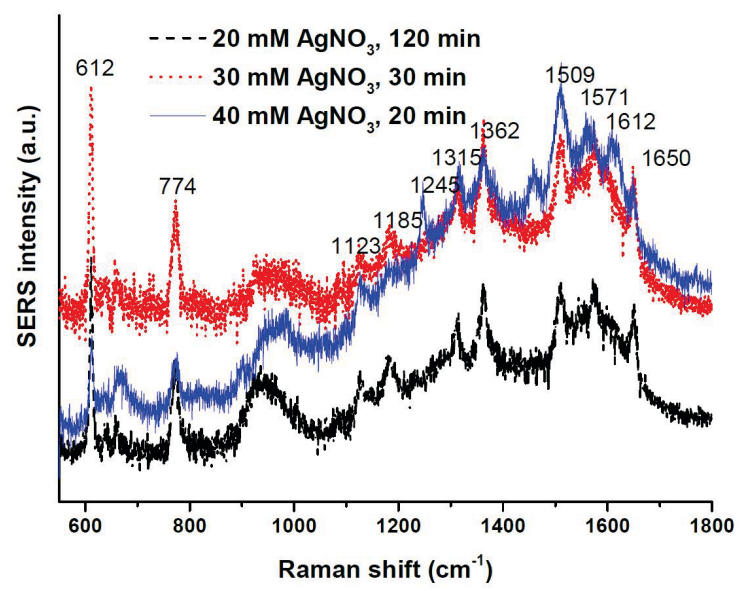

Figure 2. SERS spectra of $10^{-8} \mathrm{M}$ R6G. The measurements were carried out on the substrates synthesized for various etching in $5 \mathrm{M} \mathrm{HF}$ and 20, 30, $40 \mathrm{mM} \mathrm{AgNO}_{3}$ solutions. between the same concentrations, 40 and $30 \mathrm{mM} \mathrm{AgNO}_{3}$, as well.

It is observed that SiNWs break with the etching time and $\mathrm{AgNO}_{3}$ concentration increase. The reason for that could be mechanical stress during silver removal prior to the second step or surface drying. Also, there are no indications that longer SiNWs should improve SERS detection limit. The reason for that could be lower AgNPs density towards the SiNW bottom and therefore weaker SERS contribution. ${ }^{[18]}$

SERS measurements showed that it is possible to detect R6G molecule under maximum dilution of $10^{-8} \mathrm{M}$. Figure 2 shows SERS spectra for different etching times and $\mathrm{AgNO}_{3}$ concentrations. Two sharp, strong bands at 612 and $773 \mathrm{~cm}^{-1}$ undoubtedly confirm the R6G presence. Similar bands were observed for other samples expect for shorter etching times in the $20 \mathrm{mM} \mathrm{AgNO}_{3}$ case. Substrates prepared by short etching times and low $\mathrm{AgNO}_{3}$ concentrations should not be adequate for SERS measurements. The reason for that is based in a low 'hot spots' number i.e., AgNPs were not in the adequate vicinity to each other.

At around 1360 and $1570 \mathrm{~cm}^{-1}$ peaks due to samples degradation i.e., amorphous carbon appeared.[18] The decrease of the laser power did not solve that issue since the targeted SERS signal at lower wave numbers would decrease significantly. The very recent publication ${ }^{[17]}$ reports equal R6G detection limit of $10^{-8} \mathrm{M}$ obtained on advanced Au / Ag - silicon - 3D pyramidal substrate which confirms our samples as appropriate candidates for efficient SERS measurements.

Figure 3 demonstrates the $30 \mathrm{mM} \mathrm{AgNO}_{3}$ concentration as the optimal concentration for the $10^{-6} \mathrm{M}$ R6G solution. It should be noted that good SERS surfaces can be fabricated with lower $\mathrm{AgNO}_{3}$ concentrations as $20 \mathrm{mM}$

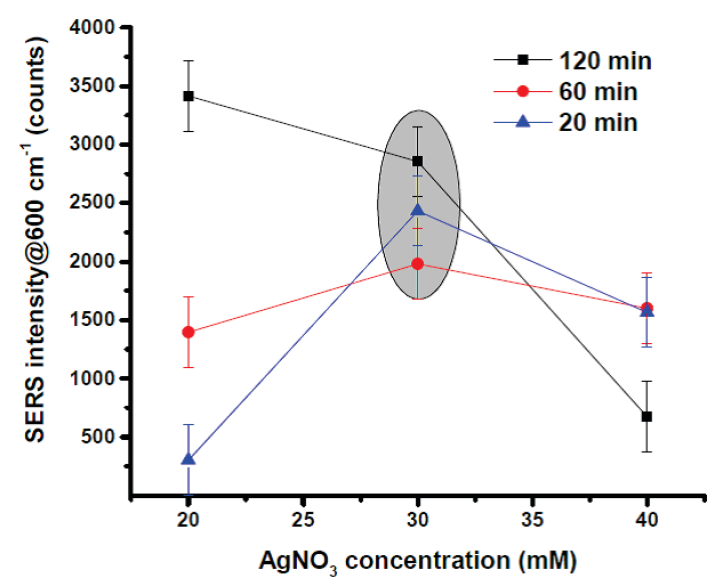

Figure 3. Intensity of $612 \mathrm{~cm}^{-1} \mathrm{R} 6 \mathrm{G}$ band for different $\mathrm{AgNO}_{3}$ concentrations parametrized for various etching time in $5 \mathrm{M}$ $\mathrm{HF}$ and $\mathrm{AgNO}_{3}$ solutions. The R6G dilution was $10^{-6} \mathrm{M}$. 
under long etching time as well. Therefore, the highest SERS amplification occurs for close $\left(30 \mathrm{mM} \mathrm{AgNO}_{3}\right.$ concentration case), rather than for more separated $(20 \mathrm{mM}$ $\mathrm{AgNO}_{3}$ concentration) or broken and irregularly grown (40 $\mathrm{mM} \mathrm{AgNO}_{3}$ ) SiNWs.

Apart from SiNWs geometry and morphology, the SERS signal depends on the silver coating. In this paper, the $\mathrm{AgNO}_{3}$ concentration used for AgNPs synthesis was the same as that used in SiNWs synthesis. Relatively well distribution of the silver nanoparticles from $50-200 \mathrm{~nm}$ size was achieved over the whole sample area. The AgNPs were mostly attached to the SiNWs top with significantly decreased number towards the SiNWs bottom. That shows that the AgNPs number and distribution on the SiNWs top is more important factor than the length of the SiNWs. Moreover, further AgNPs optimization for a specific analyte as well as the detailed substrate and SERS characterization will be carried out in the future experiments. We expect further progress in R6G detection limit and moving closer towards higher values of detection. ${ }^{[14]}$

\section{CONCLUSIONS}

The electroless wet chemical etching method was applied for the silicon nanowires synthesis utilizing hydrofluoric acid and silver nitrate aqueous solution. Particular substrate surfaces, enriched with silver nanoparticles were produced, characterized and tested for surface enhanced Raman spectroscopy applications. The results suggest the optimal $\mathrm{AgNO}_{3}$ etching concentration of $30 \mathrm{mM}$ for substrate synthesis and SERS detection limit of rhodamine $6 \mathrm{G}$ aqueous solution of $10^{-8} \mathrm{M}$.

Acknowledgment. The authors would like to thank 'Zaklada hrvatske akademije znanosti i umjetnosti' for the financial support in the frame of the project 'Površinski pojačano Ramanovo raspršenje za razvoj biokemijskih senzora', 2015. This work has been supported by Croatian Science Foundation under the project (IP-2014-09-7046). The authors are grateful to Barbara Peric for her supporting enthusiasm and novel ideas.

\section{REFERENCES}

[1] S. K Srivastava, D. Kumar, S. W. Schmitt, K. N. Sood, S. H. Christiansen, P. K. Singh, Nanotechnology 2014, 25, 175601.

[2] K. Q. Peng, Y. J. Yan, S. P. Gao, J. Zhu, Adv. Mater. 2002, 14, 1164.

[3] K. Peng, Y. Yan, S. Gao, J. Zhu, Adv. Funct. Mater. 2003, 13, 127.

[4] Y. Qu, L. Liao, Y. Li, H. Zhang, Y. Huang, X. Duan, Nano Lett. 2009, 9, 4539.

[5] X. Sun, L. Lin, Z. Li, Z. Zhang and J. Feng, Appl. Surf. Sci. 2009, 256, 916.

[6] L. Mikac, M. Ivanda, M. Gotic, A. Maksimovic, S. Trusso, C. D'Andrea, A. Foti, A. Irrera, B. Fazio, P. G. Gucciardi, Croat. Chem. Acta 2015, 88, 437.

[7] L. J. Chen, J. Mater. Chem. 2007, 17, 639.

[8] R. Ghosha, P. K. Giri, Sci. Adv. Today 2016, 2, 25230.

[9] Y. Kobayashi, S. Adachi, Jpn. J. Appl. Phys. 2010, 49, 075002.

[10] H. Um, N. Kim, K. Lee, I. Hwang, J. H. Seo, Y. J. Yu, P. Duane, M. Wober, K. Seo, Scientific Reports 2015, 5 , 11277.

[11] L. He, C. Ai, W. Wang, et al., J. Mater Sci 2016, 51, 3854.

[12] A. Convertino, M. Cuscunà, F. Martelli, M. G. Manera, R. Rella, J. Phys. Chem. C 2014, 118, 685.

[13] T. Q. N. Luong, T. A. Cao, T. C. Dao, Adv. Nat. Sci.: Nanosci. Nanotechnol., 2013, 4015018.

[14] F. Bai, M. Li, P.i Fu, R. Li, T. Gu, R. Huang, Z. Chen, B. Jiang, Y. Li, Apl. Materials 2015, 3, 056101.

[15] B. P. Azeredo, J. Sadhu, J. Ma, K. Jacobs, J. Kim, K. Lee, J. H. Eraker, X. Li, S. Sinha, N. Fang, P. Ferreira, K. Hsu, Nanotechnology 2013, 24, 225305 (8pp).

[16] K. Eumura, T. Haibara, Y. Mori, Nippon Steel Technical Report 2001, 83.

[17] C. Zhang, S. Z. Jiang, C. Yang, C. H. Li, Y. Yan Huo, X. Y. Liu, A. H. Liu, Q. Wei, S. S. Gao, X. G. Gao, B. Y. Man, Scientific Reports 2016, 6, 25243.

[18] A. C. Ferrari, J. Robertson, Phy. Rev. B. 2001, 64, 075414. 